\title{
Issues Affecting the Implementation of Inclusive Education Practices in Selected Secondary Schools in the Omaheke Region of Namibia
}

\author{
Mercy Mokaleng ${ }^{1} \&$ Andrew D. Möwes ${ }^{2, *}$ \\ ${ }^{1}$ Epukiro Roman Catholic School, Ministry of Education, Gobabis, Namibia \\ ${ }^{2}$ Department of Educational Psychology and Inclusive Education, University of Namibia, Windhoek, Namibia \\ *Correspondence: Department of Educational Psychology and Inclusive Education, University of Namibia, \\ Windhoek, Namibia. E-mail: amowes@unam.na
}

Received: December 19, $2019 \quad$ Accepted: April 15, $2020 \quad$ Online Published: May 20, 2020

doi: $10.5430 /$ jct.v9n2p78

URL: https://doi.org/10.5430/jct.v9n2p78

\begin{abstract}
The study was conducted in order to assess the issues affecting the implementation of inclusive education practices in selected secondary schools in the Omaheke region of Namibia.To achieve the objective, a quantitative research approach was followed. The population of the study was made up of secondary school teachers in the Omaheke region. Data was collected using questionnaires which were administered to a stratified sample of 90 secondary school teachers. The data was analysed by means of descriptive statistics in the form of frequencies and percentages. The results indicated that the implementation of inclusive education was hampered by various issues such as inappropriate policy development issues, teacher attitudes, lack of teacher training, inadequate support and resources, as well as curriculum issues.
\end{abstract}

Keywords: inclusive education, learners with special needs, inclusion, special education

\section{Introduction}

At the core of inclusive education is the human right to education, pronounced in the Universal Declaration of Human Rights in 1948 (UNESCO, 2000). A logical consequence of these rights is that "all children have the right to receive the kind of education that does not discriminate on any grounds, such as class, ethnicity, religion, economic status, refugee status, language, gender or disability" (UNESCO, 2000, p.102). Specifically, these rights include "access to free and compulsory education, equity, equality, inclusion, non-discrimination, the right to quality education, content and learning process" (UNESCO, 2000, p. 84).

Education as a human right has been recognized and acknowledged by various national and international organizations (Sector Policy on IE, 2013). Most of these organizations state that "learners with special needs should have access to the same quality and equivalent education as their peers" (UNESCO, 1994, p.61). The United Nations Education, Scientific and Cultural Organization (UNESCO, 1994) and the Education for All Jomtien Declaration (1990), as well as the Salamanca Statement and Framework for Action (UNESCO, 1994), state "that all individuals should have access to quality education"(p.62). The Salamanca Statement decrees that education systems should be designed and educational programmes implemented to take into account the wide diversity of learner characteristics and needs (UNESCO, 1994). Namibia, as one of the signatories of the Salamanca Statement and Framework for Action, is committed to "enhance access to education for all her citizens, and inclusive education is perceived to be the most effective approach in reaching this goal" (Sector Policy on IE, 2013, p.7).

Before Namibia's independence in 1990, learners with special needs in Namibia were taught in segregated classrooms at special schools. After Independence in 1990, Namibia however made a commitment to "integrate all people, including people with disabilities and special needs, into the society to provide basic education to all "(Republic of Namibia, 1990, p.14). The Ministry of Education was mandated to provide education and training to learners with special needs (Ministry of Education and Culture, 1993). The reasoning behind this was that, if the needs of all learners with special educational needs were met, the nation at large and people with special needs would benefit greatly. In line with the above, the National Policy on Disability (1997) was launched which 
recommends that "all children and youth with disabilities in Namibia should have the same right to education as children without disabilities"( p.17).

Despite efforts from national and international organizations to ensure that inclusive education practices are implemented, there are still learners who are taught in segregated, special schools in many parts of the world, including in Namibia(MOE, 2013). In 2012, in alignment with global trends, the Education Sector Policy on Inclusive Education for Namibia was drafted by the Ministry of Education (MOE, 2013) and is currently being implemented.

There is, however, no evidence to show that the initiatives by the Ministry of Education regarding inclusive education contained in these policy documents had been effectively implemented. Furthermore, there is also no indication of any formal evaluation that had been done on the inclusive education practices in the Omaheke region of Namibia. Moreover, it is yet to be established whether teachers in this region indeed support the provision of inclusive education or not, or whether they respond to the needs of all learners. This lack of information can limit the effective implementation of inclusive education. Since teachers are the main implementers of inclusive education, the researchers deemed it crucial to understand secondary school teachers' views regarding issues affecting the successful implementation of inclusive education practices in regular schools. Thus, the researcher's interest was triggered to find out the challenges in the implementation of inclusive education at selected secondary schools in the Omaheke region of Namibia.

\section{Method}

\subsection{Research Design}

This study followed a quantitative research approach. In this study it was not be possible for the researcher to manipulate the teachers' views directly, because it is assumed that those views regarding the issues affecting the implementation of inclusive education have already been formed. Hence it is believed that a non-experimental design is appropriate for this study. A survey was selected as the research design because of its ability to scan a wider field of issues and the fact that it relies on self-reports from respondents representing a wider population (Mertens, 2010).

\subsection{Population and Sample}

The population of the study was made up of secondary school teachers in the Omaheke region. A systematic stratified random sample of 90 teachers was drawn from the defined population. The schools from which the teachers were drawn were selected randomly from a list of schools obtained from the Ministry of Education, Arts and Culture. At each school, $50 \%$ of the respondents were randomly identified, by putting the names of all teachers in a hat and picked the names of those teachers who were to participate in the study.

\subsection{Instrumentation}

A structured questionnaire was utilized to collect the data.The decision to employ a questionnaire was predominantly taken because of the large number of respondents (Mertens, 2010).

\subsection{Procedure}

Ethical clearance was obtained from the University of Namibia. In addition to that, permission was also sought from the Ministry of Education, Arts and Culture. The researcher administered the initial questionnaire to the teachers with the help of the principals during a scheduled time that suited the majority of the teachers. At each school the researchers explained verbally the purpose of the study to the principal and teachers were also told that the information given would help improve the working conditions in the teaching profession. Thereafter the researcher collected all completed questionnaires from the teachers for analysis.

\subsection{Data analysis}

The Statistical Package for Social Sciences (SPSS) was utilized to analyze the greater part of the responses. The researcher employed descriptive analyses, such as frequencies and percentages, to compare the proportions of participants who responded in different directions.

\section{Results}

In this section the authors present the teachers' views regarding issues affecting the implementation of inclusive education. The issues identified were: policy issues, teacher attitudes, teacher training, professional support and 
resources as well as curriculum issues. The results are presented below.

\subsection{Policy Issues}

There were five statements about policy issues. The results are summarised in table 1 . In view of the trend of all the responses, it seems that the respondents generally agreed with all five statements.

Table 1. Teachers' Views Regarding Policy Issues

\begin{tabular}{|c|c|c|c|c|c|c|c|c|}
\hline \multirow[t]{3}{*}{ Statement } & \multicolumn{8}{|c|}{ Extent of agreement or disagreement with statement } \\
\hline & \multicolumn{2}{|c|}{ Disagreed } & \multicolumn{2}{|c|}{ Not sure } & \multicolumn{2}{|c|}{ Agreed } & \multicolumn{2}{|c|}{ Total } \\
\hline & $\mathrm{f}$ & $\%$ & $\mathrm{f}$ & $\%$ & $\mathrm{f}$ & $\%$ & $\mathrm{f}$ & $\%$ \\
\hline $\begin{array}{l}\text { 1. For inclusive education policies and } \\
\text { programmes to work effectively, countries } \\
\text { do require effective inclusive leadership. }\end{array}$ & 6 & 6.7 & 9 & 10.0 & 75 & 83.3 & 90 & 100 \\
\hline $\begin{array}{l}\text { 2. A weakness in policy orientation and } \\
\text { coordination undermines a holistic and } \\
\text { inclusive approach. }\end{array}$ & 1 & 1.1 & 15 & 16.7 & 74 & 82.3 & 90 & 100 \\
\hline $\begin{array}{l}\text { 3. Despite inclusive policies that are in place } \\
\text { and schools claiming to be inclusive } \\
\text { institutions, there is still exclusion to a } \\
\text { certain extent. }\end{array}$ & 8 & 8.8 & 18 & 20.0 & 64 & 71.1 & 90 & 100 \\
\hline $\begin{array}{l}\text { 4. For inclusion to be successful, teachers } \\
\text { need supportive leadership. }\end{array}$ & 1 & 1.1 & 2 & 2.2 & 86 & 95.5 & 89 & 98.9 \\
\hline $\begin{array}{l}\text { 5. School policies should make provision for } \\
\text { inclusive education and the implementation } \\
\text { thereof. }\end{array}$ & 4 & 4.4 & 5 & 5.6 & 81 & 90.0 & 90 & 100 \\
\hline
\end{tabular}

An analysis of table 1 shows that 86 of the teachers $(95.5 \%)$ felt that for inclusion to be successful, teachers need supportive leadership.

Of the total number 81 teachers $(90.0 \%)$ indicated that school policies should make provision for inclusive education and the implementation thereof. In addition $83.3 \%$ of the teachers were of the opinion that for inclusive education policies and programmes to work effectively, countries required effective, inclusive leadership, thus emphasising the importance of leadership in the implementation of inclusive education policies. Seventy four of the teachers (82.3\%) were of the view that a weakness in policy orientation and coordination undermined a holistic and inclusive approach. Of the teachers, $71.1 \%$ stated that despite inclusive policies that were in place and schools aiming to be inclusive institutions, there was still exclusion to a certain extent.

\subsection{Teacher Attitudes}

There were seven statements in this section. The results are summarised in table 2. It seemed that the teachers agreed more with statements 1 and 3-7, as opposed to statement 2, where the majority disagreed.

According to table 2 it is worth noting that $84.5 \%$ of the teachers were of the view that a lack of support for teachers, enhanced negative attitudes towards inclusive education. In addition, $81.1 \%$ of the teachers felt that large classes do not allow for inclusive education to be implemented. Futhermore, $78.9 \%$ of the teachers were of the opinion that teacher attitudes played a role in the implementation of inclusive education. Fifty seven of the teachers $(63.3 \%)$ were of the view that inclusion made too many demands on teachers. Also 56.7\% of the teachers were of the opinion that teachers' negative attitudes regarding inclusive education were a barrier to the implementation of inclusive education. Fifty teachers $(55.5 \%)$ disagreed that the success of inclusive education did not depend on teacher attitudes. Only 34 teachers $(37.8 \%)$ were of the view that teachers are confident enough to implement inclusive education. 
Table 2. Teachers' Views Regarding Attitudes

\begin{tabular}{|c|c|c|c|c|c|c|c|c|}
\hline \multirow[t]{3}{*}{ Statement } & \multicolumn{8}{|c|}{ Extent of agreement or disagreement with statement } \\
\hline & \multicolumn{2}{|c|}{ Disagree } & \multicolumn{2}{|c|}{ Not sure } & \multicolumn{2}{|c|}{ Agreed } & \multicolumn{2}{|c|}{ Total } \\
\hline & $\mathrm{f}$ & $\%$ & $\mathrm{f}$ & $\%$ & $\mathrm{f}$ & $\%$ & $\mathrm{f}$ & $\%$ \\
\hline $\begin{array}{l}\text { 1. Teacher attitudes play a role in the } \\
\text { implementation of inclusive education. }\end{array}$ & 9 & 10.0 & 9 & 10.0 & 71 & 78.9 & 89 & 98.9 \\
\hline $\begin{array}{l}\text { 2. The success of inclusive education does not } \\
\text { depend on teacher attitudes. }\end{array}$ & 50 & 55.5 & 15 & 16.7 & 25 & 27.8 & 90 & 100.0 \\
\hline $\begin{array}{l}\text { 3. Teachers are confident enough to } \\
\text { implement inclusive education. }\end{array}$ & 22 & 24.5 & 32 & 35.6 & 34 & 37.8 & 88 & 97.8 \\
\hline $\begin{array}{l}\text { 4. Teachers' negative attitudes of inclusive } \\
\text { education are a barrier to the implementation } \\
\text { of inclusive education. }\end{array}$ & 20 & 22.2 & 19 & 21.1 & 51 & 56.7 & 90 & 100.0 \\
\hline $\begin{array}{l}\text { 5. Inclusion makes too many demands on } \\
\text { teachers. }\end{array}$ & 18 & 20.0 & 15 & 16.7 & 57 & 63.3 & 90 & 100.0 \\
\hline $\begin{array}{l}\text { 6. Lack of support for teachers enhance } \\
\text { negative attitudes towards inclusive } \\
\text { education. }\end{array}$ & 6 & 6.6 & 8 & 8.9 & 76 & 84.5 & 90 & 100.0 \\
\hline $\begin{array}{l}\text { 7. Teachers feel that large classes do not allow } \\
\text { for inclusive education. }\end{array}$ & 10 & 11.1 & 7 & 7.8 & 73 & 81.1 & 90 & 100.0 \\
\hline
\end{tabular}

\subsection{Teacher Training}

There were six statements about teacher training. The results are summarised in Table 3. In view of the trend of all the responses, it seems that the respondents agreed with all six statements.

Table 3. Teachers' Views Regarding Teacher Training

\begin{tabular}{|c|c|c|c|c|c|c|c|c|}
\hline \multirow[t]{3}{*}{ Statement } & \multicolumn{8}{|c|}{ Extent of agreement or disagreement with statement } \\
\hline & \multicolumn{2}{|c|}{ Disagree } & \multicolumn{2}{|c|}{ Not sure } & \multicolumn{2}{|c|}{ Agree } & \multicolumn{2}{|c|}{ Total } \\
\hline & $\mathrm{f}$ & $\%$ & $\mathrm{f}$ & $\%$ & $\mathrm{f}$ & $\%$ & $\mathrm{f}$ & $\%$ \\
\hline $\begin{array}{l}\text { 1. In order for inclusion to be successful, } \\
\text { teachers should be prepared in terms of } \\
\text { appropriate and professional training together } \\
\text { with on-going training. }\end{array}$ & 5 & 5.5 & 2 & 2.2 & 83 & 92.2 & 90 & 100.0 \\
\hline $\begin{array}{l}\text { 2. Pre-service teacher training adequately } \\
\text { equips teachers to deal with diverse educational } \\
\text { needs in the classroom. }\end{array}$ & 19 & 21.2 & 13 & 14.4 & 58 & 64.4 & 90 & 100.0 \\
\hline $\begin{array}{l}\text { 3. Teachers do lack knowledge in working with } \\
\text { learners with special needs. }\end{array}$ & 8 & 8.9 & 6 & 6.7 & 74 & 82.2 & 88 & 97.9 \\
\hline $\begin{array}{l}\text { 4. Lack of proper teacher training causes } \\
\text { unwillingness to work with learners with special } \\
\text { needs. }\end{array}$ & 12 & 13.3 & 8 & 8.9 & 70 & 77.8 & 90 & 100.0 \\
\hline $\begin{array}{l}\text { 5. In order for inclusion to succeed, teachers } \\
\text { must receive in-service training in educating } \\
\text { learners with special educational needs. }\end{array}$ & 2 & 2.2 & 3 & 3.3 & 85 & 94.4 & 90 & 100.0 \\
\hline $\begin{array}{l}\text { 6. Teachers need sufficient training to } \\
\text { implement inclusive education. }\end{array}$ & 5 & 5.5 & 1 & 1.1 & 84 & 93.3 & 90 & 100.0 \\
\hline
\end{tabular}


A perusal of table 3 reveals that 85 of the teachers $(94.4 \%)$ were of the view that in order for inclusion to succeed teachers must receive in-service training in educating learners with special educational needs. Eighty four of the teachers $(93.3 \%)$ felt that teachers needed sufficient training to implement inclusive education. In addition 83 of teachers $(92.2 \%)$ were of the opinion that in order for inclusion to be successful, teachers should be prepared in terms of appropriate and professional qualifications combined with on-going in-service training.

Furthermore 74 of the teachers $(82.2 \%)$ were of the view that teachers lacked knowledge regarding working with learners with special needs. Seventy teachers (77.8\%) felt that a lack of proper teacher training caused unwillingness to work with learners with special needs. In addition fifty eight of the teachers $(64.4 \%)$ expressed the view that pre-service teacher training adequately equips them to deal with diverse educational needs in the classroom.

\subsection{Adequate Support and Resources}

There were eight statements in this section. The responses are summarized in table 4 . It seemed that most of the teachers agreed more readily with statements $1-3$ and 5-8 than statement 4 .

Table 4. Teachers' Views Regarding Adequate Support and Resources

\begin{tabular}{|c|c|c|c|c|c|c|c|c|}
\hline \multirow[t]{3}{*}{ Statement } & \multicolumn{8}{|c|}{ Extent of agreement or disagreement with statement } \\
\hline & \multicolumn{2}{|c|}{ Disagree } & \multicolumn{2}{|c|}{ Not sure } & \multicolumn{2}{|c|}{ Agree } & \multicolumn{2}{|c|}{ Total } \\
\hline & $\mathrm{f}$ & $\%$ & $\mathrm{f}$ & $\%$ & $\mathrm{f}$ & $\%$ & $\mathrm{f}$ & $\%$ \\
\hline $\begin{array}{l}\text { 1. Limited access to support services and } \\
\text { the unavailability of resources can } \\
\text { influence teachers' ability to implement } \\
\text { inclusive education. }\end{array}$ & 10 & 11.2 & 7 & 7.8 & 73 & 81.1 & 90 & 100.0 \\
\hline $\begin{array}{l}\text { 2. Adequate support must be available to } \\
\text { assist mainstream teachers in meeting the } \\
\text { special needs of learners in inclusive } \\
\text { classes. }\end{array}$ & 5 & 5.5 & 1 & 1.1 & 84 & 93.3 & 90 & 100.0 \\
\hline $\begin{array}{l}\text { 3. Teachers do not receive sufficient and } \\
\text { fundamental support from advisory } \\
\text { personnel. }\end{array}$ & 8 & 8.9 & 11 & 12.2 & 71 & 78.9 & 90 & 100.0 \\
\hline $\begin{array}{l}\text { 4. Schools should not have expert personnel } \\
\text { (educational psychologists, remedial } \\
\text { teachers) available in schools to assist with } \\
\text { the implementation of inclusive education. }\end{array}$ & 71 & 78.9 & 4 & 4.4 & 15 & 16.7 & 90 & 100.0 \\
\hline $\begin{array}{l}\text { 5. Adequate resources should be allocated } \\
\text { to schools to cater for the diverse needs of } \\
\text { all learners. }\end{array}$ & 3 & 3.3 & 1 & 1.1 & 86 & 96.6 & 90 & 100.0 \\
\hline $\begin{array}{l}\text { 6. Co-teaching with a remedial teacher will } \\
\text { enhance the quality of inclusive education. }\end{array}$ & 4 & 4.4 & 13 & 14.4 & 72 & 80.0 & 89 & 98.9 \\
\hline $\begin{array}{l}\text { 7. The backup help from specialist teachers } \\
\text { is an essential factor for successful } \\
\text { inclusion. }\end{array}$ & 4 & 4.4 & 4 & 4.4 & 82 & 91.2 & 90 & 100.0 \\
\hline $\begin{array}{l}\text { 8. Computers could be a useful teaching aid } \\
\text { in making successful regular classes, which } \\
\text { include learners with and without special } \\
\text { educational needs. }\end{array}$ & 7 & 7.8 & 16 & 17.8 & 67 & 74.4 & 90 & 100.0 \\
\hline
\end{tabular}

An analysis of table 4 shows that 86 of the teachers (96.6\%) were of the opinion that adequate resources should be allocated to schools to cater for the diverse needs of all learners. Of the teachers, $84(93.3 \%)$ felt that adequate support should be available to assist mainstream teachers in meeting the special needs of learners in inclusive 
classes.

Of the teachers $82(91.2 \%)$ were of the view that the backup help from specialist teachers was an essential factor for successful inclusion. Seventy three of the teachers (81.1\%) felt that limited access to support services and the unavailability of resources could influence teachers' ability to implement inclusive education.

Of the total number of teachers, $72(80.0 \%)$ were of the view that co-teaching with a remedial teacher would enhance the quality of inclusive education. Seventy one teachers (78.9\%) were of the opinion that teachers did not receive sufficient and fundamental support from advisory personnel. Also 71 teachers (78.9\%) disagreed that schools should not have expert personnel (educational psychologists, remedial teachers) available in schools to assist with the implementation of inclusive education. In addition 67 of teachers (74.4\%) felt that computers could be a useful teaching aid in making successful regular classes, which include learners with and without special educational needs.

\subsection{Curriculum Issues}

There were six statements in this section. The results about curriculum issues are presented in Table 5. It seems that the teachers agreed with all six statements.

Table 5. Teachers' Views Regarding Curriculum Issues

\begin{tabular}{|c|c|c|c|c|c|c|c|c|}
\hline \multirow[t]{3}{*}{ Statement } & \multicolumn{8}{|c|}{ Extent of agreement or disagreement with statement } \\
\hline & \multicolumn{2}{|c|}{ Disagree } & \multicolumn{2}{|c|}{ Not sure } & \multicolumn{2}{|c|}{ Agree } & \multicolumn{2}{|c|}{ Total } \\
\hline & $\mathrm{f}$ & $\%$ & $\mathrm{f}$ & $\%$ & $\mathrm{f}$ & $\%$ & $\mathrm{f}$ & $\%$ \\
\hline $\begin{array}{l}\text { 1. Inflexible curriculum does not allow for } \\
\text { learners with and without special needs to } \\
\text { be included in all lessons. }\end{array}$ & 18 & 20.0 & 16 & 17.8 & 56 & 62.3 & 90 & 100.0 \\
\hline $\begin{array}{l}\text { 2. Curriculum should allow for everyday } \\
\text { survival skills. }\end{array}$ & 7 & 7.7 & 7 & 7.8 & 75 & 83.4 & 89 & 98.9 \\
\hline $\begin{array}{l}\text { 3. Teachers should be allowed to teach at } \\
\text { the learners' pace of learning. }\end{array}$ & 7 & 7.8 & 8 & 8.9 & 73 & 81.1 & 88 & 97.8 \\
\hline $\begin{array}{l}\text { 4. A flexible curriculum grants all children } \\
\text { a chance to learn and benefit from } \\
\text { education }\end{array}$ & 8 & 8.9 & 4 & 4.4 & 77 & 85.5 & 89 & 98.9 \\
\hline $\begin{array}{l}\text { 5. Teachers cannot implement inclusive } \\
\text { education because curriculum is } \\
\text { content-loaded }\end{array}$ & 19 & 21.1 & 14 & 15.6 & 57 & 63.3 & 90 & 100.0 \\
\hline $\begin{array}{l}\text { 6. Teachers follow the curriculum to detail } \\
\text { which makes it impossible to pay attention } \\
\text { to learners with special needs. }\end{array}$ & 12 & 13.3 & 9 & 10.0 & 69 & 76.7 & 90 & 100.0 \\
\hline
\end{tabular}

Judging from table 5 it is worth noting that 77 of the teachers (85.5\%) were of the view that a flexible curriculum granted all children a chance to learn and benefit from education. Of the total number of teachers, $83.4 \%$ agreed that the curriculum should allow for everyday survival skills. Seventy three of the teachers $(81.1 \%)$ were of the opinion that teachers should be allowed to teach at the learners' pace of learning. Sixty nine teachers $(76.6 \%)$ felt that if teachers followed the curriculum to detail, it would be impossible to pay attention to learners with special needs.

Of the total number of teachers 57 (63.3\%) agreed that teachers could not implement inclusive education because the curriculum was content-loaded. In addition fifty six teachers (62.3\%) were of the view that an inflexible curriculum did not allow for learners with and without special needs to be included in all lessons.

\section{Discussion}

The present data lends support to findings reported by other researchers with regard to issues that affect the implementation of inclusive education (Qeleni,2013; Mittler, 2005; Mambo, 2011; Precey, 2011; Madrid, 2015; Cole, 
2006; Zulu, 2007; Newton, Cambridge, \& Hunter-Johnson, 2014; Kurniawati, Minnaert, Mangusong, \& Ahmed, 2012; Al-Zyodi, 2006; Peakock, 2016; Mutisya, 2010; Marimuthu \& Cheong, 2014; Haitembu, 2014; Norwich \& Lewis, 2007; Horne \& Timmons, 2009; Mwaura, 2004; Petriwskyj, 2010, Calero \& Benasco, 2015, Chimhenga, 2016; Miles, Miller, Lewis, \& Kroft, 2001; Möwes, 2002; Stofile, 2008; Budginaité, Siarova, Sternadel, Mackonyté, \& Spurga, 2016; Mongwaketse, 2011). Some of these issues include inappropriate policy development issues, teacher attitudes, a lack of teacher training, inadequate support and resources, as well as curriculum issues.

\subsection{Inappropriate Policy Development Issues}

The findings of the study indicate that the majority of teachers felt that for inclusion to be successful, teachers need supportive leadership.This finding consistent with research donne by Qeleni (2013) who noted that school leaders influence inclusive school change when they provide teachers with apropriate support. This could imply that teachers need support from their supervisors regarding inclusive education in order to support efforts in teaching learners with special needs and to set up simultaneous, practical structures and routines for dealing with learners with special needs. In addition, it could mean that if the inclusive policy is not supported by the leadership, it could affect its implementation.

The second rank concerns the statement that school policies should make provision for inclusive education. The study reveals that an overwhelming majority of the teachers felt that school policies should make provision for inclusive education and its implementation. This is in line with the Sector Policy of Inclusive Education in Namibia that stipulates that "the whole education system at its various levels of functiontioning should be inclusive (Sector Policy on IE, 2013, p.10)." The explanation could be that, if inclusive education is not central to the education, it cannot be implemented, even if policies are in place.

The third rank, relating to policy issues, states that for inclusive education policies and programmes to work effectively, countries require effective, inclusive leadership. The majority of the teachers agreed with the statement. This finding is consistent with those of Precey (2011) that, for inclusive education policies and programmes to work effectively, countries require inclusive leadership. This could imply that current leadership regarding inclusive education in the Omaheke region is not efficient enough to ensure that programmes and policies are implemented efficiently.

The fourth rank, relating to policy issues, indicates that a weakness in policy orientation and coordination undermines a holistic and inclusive approach. An overwhelming majority of the teachers agreed with the statement. This finding is consistent with research conducted by Madrid (2015) who found there are gaps between policy and its implementation. The message that could be communicated here is that teachers felt that there was a weakness in the orientation and coordination of the current policy on inclusive education.

The fifth rank, relating to policy issues, states that despite inclusive policies that were in place and schools claiming to be inclusive institutions, there was still exclusion to a certain extent. This study reveals that most of the teachers agreed that there was still exclusion to a certain extent, even where policies were in place and schools claiming to be inclusive institutions. The findings of this study are consistent with those of Mambo (2011) who concluded that teachers were not fully aware of the inclusive education policy and practice, and that poor implementation of inclusive education policy was due to a lack of appropriate training and professional development.

The message here could be that schools are still reluctant to include learners with special needs even though inclusive education policies are in place. Additionally, this could create exclusion to a certain extent in schools.

\subsection{Teacher Attitudes}

The findings of the study provided evidence that the majority of teachers were of the view that there was a lack of support for teachers, which enhances negative attitudes towards inclusive education.

This finding is consistent with that of other researchers, such as Zulu (2007) and Newton, Cambridge and Hunter-Johnson (2014) who are of the opinion that teachers' negative attitudes are due to a lack of knowledge and skills, as well as a lack of training and insufficient support. The message here could be that teachers' negative attitudes are created by a lack of support from advisory personnel and, as a result, inclusive education becomes a burden to them.

The second rank concerns teachers feeling that large classes did not allow for inclusive education. These findings are consistent with those of Newton, Cambridge and Hunter-Johnson (2014) that negative attitudes are caused by large class sizes. The message that could be communicated here is that teachers are overwhelmed by large classes; therefore, they cannot include all learners and give enough attention to the special needs of all learners. 
The third rank concerns the statement that teacher attitudes play a role in the implementation of inclusive education. The data show that more than half of the teachers agreed that teacher attitudes played a role in the implementation of inclusive education. This finding is supported by Al-Zyodi (2006) and Newton, Cambridge and Hunter-Johnson (2014) who found that the severity and nature of the disabling condition, together with a lack of skills, influenced teachers' attitudes to work with learners with special needs. This could mean that teachers are not sufficiently trained in dealing with learners with special needs, and feel saddled to work with such learners. In addition, this could then create negative attitudes, especially if teachers do not know how to deal with specific issues regarding learners with special needs.

The fourth rank concerns the statement that inclusion makes too many demands on teachers. The study reveals that the majority of the teachers agreed that inclusion made too many demands on teachers. This finding is in line with Peacock (2016) who found that inclusive education made too many demands on teachers. This could imply that teachers lack knowledge and support regarding inclusive education and thus feel being saddled. Additionally, if teachers do not know how to include learners with special needs in their classes, it could create a feeling of too many demands made on them.

The fifth rank concerns the statement that teachers' negative attitudes about inclusive education were a barrier to the implementation of inclusive education. The data show that more than half of the teachers agreed that teachers' negative attitudes about inclusive education were a barrier to the implementation of inclusive education. These findings are consistent with those of Peacock (2016) and Al-Zyoudi (2006) who found that teachers' attitudes were the greatest barrier to inclusive education. The majority of the respondents, furthermore, stated that the attitudes of teachers were influenced by the lack of support. This could imply that teachers do not get enough support regarding inclusive education which, in turn, creates negative attitudes. These negative attitudes become a barrier because teachers are not willing or able to work with learners with special needs.

The sixth rank concerns the statement that the success of inclusive education does not dependent on teachers' attitudes. This study reveals that half of the teachers disagreed that the success of inclusive education did not depend on teachers' attitudes. This finding is in contrast with the findings of Zulu (2007) who found that the success of inclusive education depended greatly on teachers. Additionally, she states that, for inclusive education to be successful, educators need to be prepared and properly trained. The message here could be that teachers do accept that their attitudes are a barrier to inclusive education. In addition, it could be that teachers feel they do not get the necessary support from supervisors, hence, the feeling that the success of inclusive education does not depend on them.

The seventh rank concerns the statement that teachers are confident enough to implement inclusive education. The study reveals that the majority of the teachers agreed that teachers were confident enough to implement inclusive education. These findings are contrary to those of Mastropieri and Scruggs (as cited in Mutisya, 2010) who found that teachers were reluctant or unwilling to teach learners with special needs because they felt that they did not have appropriate training, sufficient time, other materials and resources to enable them to work with learners with special needs. This could mean that teachers would be more confident to implement inclusive education if they receive adequate training and support from specialist and advisory personnel.

\subsection{Teacher Training}

The first rank concerns the statement that, in order for inclusion to succeed, teachers must receive in-service training in educating learners with special educational needs. This study reveals that an overwhelming majority of the teachers agreed with this statement. This finding is in line with that of Marimuthu and Cheong (2014) who found that, for inclusive education to be successful, it requires well-equipped, knowledgeable and competent teachers who are able to foster the required values, confidence and support in learners with special needs. The message could be that most teachers are not trained in teaching learners with special needs, hence, the need for in-service training.

The second rank concerns the statement that teachers need sufficient training to implement inclusive education. The vast majority of the teachers agreed that teachers needed sufficient training to implement inclusive education. This finding is consistent with that reported by Zulu (2007) who found that, for the implementation of inclusion to be successful, educators should be prepared in terms of appropriate and professional training, together with adequate ongoing training. This could mean that if teachers are well-trained, they will not have any difficulty with the implementation of inclusive education.

The third rank concerns the statement that, in order for inclusion to be successful, teachers should be prepared in terms of appropriate and professional training, together with on-going training. More than half of the teachers agreed 
with the statement. This finding is consistent with that reached by Horne and Timmons (2009) who found that, to implement inclusion successfully anywhere in the world, teachers must have adequate training, sufficient support and positive attitudes. This could mean that teachers realised that if they were to be successful, they needed to be appropriately prepared for the task. Additionally, it could be that teachers realised that they were not properly trained; therefore, they saw the need for in-service training according to the challenges they faced.

The fourth rank concerns the statement that teachers lack knowledge in working with learners with special needs. The data reveal that an overwhelming majority of teachers agreed that teachers did lack knowledge in working with learners with special needs. This finding is consistent with that reported by Haitembu (2014) who found that a lack of in-service teacher training and a lack of information and knowledge about inclusive education were some of the challenges faced by teachers. The message that is communicated here could be that teachers had not received sufficient information and training on special needs; therefore, they did not feel capable enough to work with learners with special needs.

The fifth rank concerns the statement that a lack of proper teacher training caused unwillingness to work with learners with special needs. The study reveals that the majority of the teachers agreed with the statement. This finding is supported by Norwich and Lewis (2007) who found that, before implementation, teachers needed to be trained and educated to enable them to acquire basic skills and practical knowledge. This could mean that, if teachers are not properly trained, they might be unwilling to work with learners with special educational needs. Learners with special educational needs may suffer badly due to this unwillingness of teachers to assist or support them.

The sixth rank concerns the statement that pre-service teacher training equips teachers adequately to deal with diverse educational needs in the classroom. The data show that more than 50 percent of the teachers agreed with the statement. This finding is consistent with that of Haitembu (2014) who found that, even if education officials were aware of their responsibilities in providing inclusive education, they had mixed understandings of the importance of those responsibilities. This could mean that, even if teachers were trained at teacher training institutions regarding how to work with learners with special needs, they lacked the understanding of how to put theory into practice in the classroom.

\subsection{Adequate Support and Resources}

The first rank concerns the statement that adequate resources should be allocated to schools to cater for the needs of all learners. This study reveals that significantly more teachers agreed that adequate resources should be allocated to schools to cater for the needs of all learners. This finding is consistent with that of Randiki (as cited in Mutisya, 2010) who found that the available resources should be in place where everybody who needed them could easily access them.

The message here could be that teachers find it challenging to deal with learners with special needs due to a lack of enough resources in schools. Additionally, it could be that resources are not available; therefore, the needs of learners are not catered for.

The second rank concerns the statement that adequate support must be available to assist mainstream teachers in meeting the special needs of learners in inclusive classes. This study shows that significantly more teachers agreed with the statement. The finding is consistent with findings by Mwaura (2004) who found that sufficient learning resources and support services needed to be made available and put in place to support inclusive education, and that it would be excellent if adequate support could be provided to mainstream teachers to meet the needs of learners in inclusive classes. This support can be in terms of assistant teachers in each class. The deduction that could be made here is that teachers are of the opinion that support is not sufficient to assist them in their classes in order for them to address the special needs of learners. It could be that these teachers find it challenging to address learners' needs due to having more learners in class; therefore, they feel the need for sufficient support in terms of assistant teachers and ample learning resources.

The third rank concerns the statement that backup help from specialist teachers is an essential factor for successful inclusion. The study reveals that an overwhelming majority of the teachers agreed with the statement. This is in line with Petriwskyj (2010) who suggests that adequate support in terms of remedial and special educators must be available to assist mainstream teachers in meeting the special needs of learners and challenges in inclusive education classes. The message here could be that, with the current status quo, teachers realise that inclusive education will experience challenges if they do not receive backup help from specialists. Additionally, it could be that teachers recognise the need for specialist teachers to assist with learners' diverse needs.

The fourth rank comprises the statement that limited access to support services and the availability of resources can 
influence teachers' ability to implement inclusive education effectively. The data show that significantly more teachers agreed with the statement. This finding is in line with that of Petriwskyj (2010), namely that limited access to support services, the availability of resources and outcome pressures, as well as limited professional learning about diversity influenced teachers understanding of the implementation of inclusive education. The deduction that could be made is that teachers realise that they have limited access to support services and resources; therefore, they find it challenging to implement inclusive education effectively.

The fifth rank concerns the statement that co-teaching with a remedial teacher will enhance the quality of inclusive education. A great majority of the teachers agreed. This finding is supported by Calero and Benasco (2015) who found that a lack of support, together with the need for additional resources from educational authorities, was a major factor for professionals to attend to learners with special needs. The message here could be that teachers find it challenging to attend to the diverse needs of learners; therefore, they require remedial teachers to co-teach with them in order for inclusive education to be enhanced.

The sixth rank concerns the statement that teachers do not receive sufficient and fundamental support from advisory personnel. This study shows that a vast majority of the teachers agreed with the statement. This finding is in line with that of Petriwskyj (2010), namely that adequate support in terms of experts, educational psychologists, remedial and special educators, sufficient teacher training, ample resources, collaboration and accessibility, building awareness and including teachers must be available to assist mainstream teachers to meet the special needs and challenges in inclusive classes when decisions are made or when materials are developed. It could be that teachers are aware of the diverse needs of learners; however, they do not receive sufficient and fundamental support. Therefore, they require adequate support and specialists to assist in addressing the needs of all learners.

The seventh rank is whether schools should not have expert personnel (educational psychologists, remedial teachers) available in schools to assist with the implementation of inclusive education. The data of this study show that an overwhelming majority of the teachers agreed with the statement. This finding is contrary to the finding by Calero and Benasco (2015), namely that a lack of support, together with the need for additional resources and for professionals to attend to learners with special needs from educational authorities, was a major factor. The deduction that could be made here is that schools do require expert personnel to assist with the diverse needs of all learners and to assist with the successful implementation of inclusive education.

The eight rank concerns the statement that computers could be useful teaching aids in making successful regular classes, which include learners with and/or without special educational needs. This study reveals that the majority of the teachers agreed with the statement. This finding is consistent with that of Chimhenga (2016), who concluded that a lack of resources, such as computers, trained teachers, finances, classrooms, among others for use by learners with special needs, affect the implementation of inclusive education. The message here could be that teachers are aware of the diverse needs of learners; therefore, they require assistive devices to meet the needs of those learners.

\subsection{Curriculum Issues}

This study reveals that the vast majority of teachers agreed that a flexible curriculum granted all children a chance to learn and benefit from education. This finding is supported by Miles, et.al. (2001), namely that where there is a flexible curriculum, all children have a chance to learn and benefit from education, and their achievements can be recognised. The message here could be that teachers understand that inclusion will not be achieved in schools unless modifications are made to the existing curriculum in regular schools.

The second rank concerns the statement that the curriculum should allow for everyday survival skills. This finding is supported by Möwes (2002) who argues that the curriculum must be sufficiently differentiated to allow for differences in learners' abilities and circumstances. The data show that a higher proportion of teachers agreed that the curriculum should allow for everyday, survival skills. A possible explanation for this could be that when learners are equipped with these skills, they would be able to support themselves in future. These survival skills would enable them to face the world and also start their own businesses without waiting on anyone to provide them with jobs.

The third rank concerns the statement that teachers should be allowed to teach at the learners' pace of learning. This study reveals that a higher fraction of teachers agreed with the statement. The findings of this study are in line with that of Stofile (2008), namely that the curriculum needs to be accessible and responsive to the needs of all learners in order to enable schools to accommodate diversity in the learner population. The explanation could be that if teachers teach according to the learners' pace, they can ensure the child learns in a way that he or she is able to. One would be able to bridge a gap that others may not be able to. Additionally, by tailoring your lesson plan to the learners' pace, you might help other children, who do not display difficulties, to learn in new and innovative ways. 
The fourth rank concerns the statement that teachers follow the curriculum to detail which makes it impossible to pay attention to learners with special needs. The study shows that a higher percentage of teachers agreed with the statement. This finding is consistent with those of Budginaité, et.al. (2016), namely that a curriculum that is too rigid, centralised and fails to reflect the diversity of the implicated learners can have a negative impact on the learning process. This could mean that, since teachers need to complete the curriculum within a certain time frame, it could be a challenge to accommodate learners with special educational needs while struggling to complete the curriculum on time.

The fifth rank concerns the statement that teachers cannot implement inclusive education because the curriculum is content-laden. This study reveals that more teachers agreed with the statement. The finding of this study is consistent with that of Mongwaketse (2011) who suggests that the current curricula employed in mainstream schools are not designed on the basis of flexibility and appear to be content heavy. This could imply that teachers find the current curriculum content heavy and that with many learners in classes, there may not be enough time to cater for the wide range of different needs of all learners in the classroom.

The sixth rank concerns the statement that the inflexible curriculum does not allow for learners with and without special needs to be included in all lessons. The data of this study show that more than half of the teachers agreed with the statement. This finding is supported by Möwes (2002) posits that the curriculum should be broad and strife to bring all learners into contact with an agreed range of learning and experience. The finding is, furthermore, also consistent with findings by Mittler (2005), namely that the curriculum must be sensitive and responsive to the diverse cultures, beliefs and values and that it has to be structured and implemented in such a way that all learners can access it. The deduction that could be made here is that the curriculum is inadequate to cater for the diverse needs of all learners. It could also be that the curriculum does not allow for all learners to be included all the time.

\section{Recommendations}

The recommendations that follow emanate from the results reported earlier and their discussion.

- It is recommended that the Ministry of Education should provide teachers with supportive leadership to ensure that the implementation of inclusive education is successful.

- It is also recommended that the Ministry of Education should provide teachers with sufficient support to curb negative attitudes to inclusive education.

- It is further recommended that in order for inclusion to succeed, the Ministry of Education should offer in-service training in teaching learners with special educational needs to teachers.

- It is also recommended that the Ministry of Education should provide schools with adequate resources to cater for the diverse needs of all learners.

- It is also recommended that the current curriculum should be adapted to ensure that the diverse needs of learners are catered for and that all learners are granted a chance to learn.

\section{Conclusion}

The present study looked at factors affecting the implementation of inclusive education practices in selected secondary schools in the Omaheke region. The study concludes that challenges that hamper inclusive education manifest themselves in the lack of supportive leadership, support for teachers, training, resources, as well as in the inflexible curriculum.

Finally, despite efforts from national and international organisations to ensure that inclusive education practices are implemented in Namibian schools, there is still exclusion to a certain extent. Therefore, the Ministry of Education, teachers, parents and all other stakeholders are encouraged to study these observed results and strive to devise solutions that ensure that inclusive education is achieved.

\section{Acknowledgements}

We would like to express our gratitude to the University of Namibia for creating a basis for the initial project. This article and the primary research on which it is based would not have been possible without the support of the University of Namibia. The primary research has been uploaded into the Universities open access repository in 
compliance with the University scholarly communications policy.

\section{References}

Al-Zyoudi, M. (2006). Teachers' attitudes towards inclusive education in Jordanian schools. International Journal of Special Education, 21(2), 55-62.

Budginaité, I., Siarova, H., Sternadel, D., Mackonyté G., \& Spurga, S. A. (2016). Policies and practice for equality and inclusion in and through education. European Commission.

Calero, J., \& Benasco, X. P. (2015). Quality factors of inclusive education in Europe: An exploration. European Network on Inclusive Education and Disability, Union Europe.

Chimhenga, S. (2016). Resource material barriers: The challenge of implementing inclusive education in primary schools of Zimbabwe. Global Journal of Advanced Research, 3(6), 526-532.

Cole, C. (2006). Closing the achievement Gap Series: Part 3. What is the impact of NLCB on the inclusion of Students with Disabilities. Centre for Evaluation and Education Policy, 4(11).

Haitembu, R. K. (2014). Assessing the provision of inclusive education in the Omusati region. Unpublished master's thesis, University of Namibia, Windhoek, Namibia.

Horne, P. E., \& Timmons, V. (2009). Making it work: Teachers' perspectives on inclusion. International Journal of Inclusive Education, 13(3), 273-286. https://doi.org/10.1080/13603110701433964

Kurniawati, F., Minnaert, A., Mangusong, F., \& Ahmed, W. (2012). Empirical study on primary school teachers' attitudes towards inclusive education in Jakarta, Indonesia. Procedia-Social and Behavioral Sciences, 69, 1430-1436. https://doi.org/10.1016/jsbspro.2012.12.082

Madrid, M. D. (2015). Implementing inclusive education in Namibian primary schools: From policies to practice. Unpublished master's thesis, University of Oulu. Finland.

Mambo, J. A. (2011). Exploring teachers' perceptions of the implementation of inclusive education in a regular primary school: A Papua New Guinea study. Thesis for Master's Degree in Education, Victoria University of Wellington.

Marimuthu, S., \& Cheong, L. S. (2014). Inclusive education for social transformation. Procedia - Social and Behavioral Sciences, 172, 317-322. https://doi.org/10.1016/j.sbspro.2015.01.370

Mertens, D. M. (2010). Research and evaluation in education and psychology: Integrating diversity with quantitative, qualitative, and mixed methods (3rd ed.). USA London: Sage Publications.

Miles, S., Miller, S., Lewis, I., \& Kroft, M. (2001). Schools for all: Including disabled children in education. London: UK.

Ministry of Education. (MoE). (2013). Sector Policy on Inclusive Education. Windhoek: John Meinert Printing (Pty)Ltd.

Ministry of Education and Culture (MEC). (1993). Towards education for all: A Developmental brief for Education, Culture and Training. Windhoek: Gamsberg Macmillan.

Mittler, P. (2005). Building bridges between special and mainstream services. Asia Pacific Disability Rehabilitation Journal, 16(1).

Mongwaketse. M. E. O. (2011). Implementing inclusive education in Botswana primary school setting: An exploration of teachers' understandings of curriculum, curriculum adaptations and children who have learning difficulties. Dissertation in Doctor of Education in Special needs. University of Exeter, England: UK..

Möwes, A. D. (2002). The views of educators regarding inclusive education in Namibia. Unpublished doctoral dissertation, University of Stellenbosch, Stellenbosch.

Mutisya, C. M. S. (2010). Factors influencing inclusion of learners with special needs in regular primary schools in Rachuonyo districy, Kenya. Master's thesis, Kenyatta University, Kenya.

Mwaura, J. W. (2004). Factors affecting the implementation of inclusive education policy of children with special needs in public primary schools in Kikuyu division, Kiambu district. Master's thesis.

Newton, N., Cambridge, J., \& Hunter-Johnson, Y. (2014). Teachers' perceptions of inclusive education and its 
implication for adult education in the Bahamas. College of the Bahamas.

Norwich, B., \& Lewis, A. (2007). How specialized is teaching children with disabilities and difficulties? Journal of Curriculum Studies, 39(2), 100-110. https://doi.org/10.1080/00220270601161667

Peacock, D. P. (2016). Teacher perceptions of the effectiveness of inclusion in elementary classroom settings. Dissertation for the degree of Doctor of Philosophy, Walden University.

Petriwskyj, A. (2010). Diversity and inclusion in the early years. International Journal of Inclusive education, 14(2), 160-170. https://doi.org/10.1080/13603110802504515

Precey, R. (2011). Inclusive leadership for inclusive education: The utopia worth working towards. Wspótczesne Zarzadzanie, 2, 35-44.

Qeleni, M. T. (2013). Leadership for Inclusion: School leadership that motivates teachers to built inclusive classrooms. Unpublished master's dissertation, University of Oslo. Norway.

Republic of Namibia. (1991). The constitution of the Republic of Namibia. Office of the Prime Minister, Windhoek, Namibia. https://doi.org/10.11619/africa1964.1991.39_51

Republic of Namibia. (1997). National policy on disability. Office of the Prime Minister, Windhoek, Namibia.

Stofile, S. Y. (2008). Factors affecting the implantation of inclusive education policy: A case study in one province in South Africa. Published Doctoral Thesis, University of Western Cape.

UNESCO. (1990). World Declaration on Education For All and Framework For Action To Meet Basic Learning Needs. Jomtien, Thailand: UNESCO.

UNESCO. (1994). The Salamanca Statement and Framework for Action on Special Needs Education: Access and Quality. Salamanca, Spain: UNESCO.

UNESCO. (2000). The Dakar framework for action. Paris: UNESCO.

Zulu, D. N. (2007). Implementation of inclusive education. A Masters' Thesis. Durban. University of Zululand. 